$\begin{aligned} \begin{array}{l}\text { Sky high } \\ \text { Spiralling costs of } \\ \text { space station put } \\ \text { research in doubt } \\ \text { p399 }\end{array} & \begin{array}{l}\text { War of words } \\ \text { Eruption books } \\ \text { reignite volcano } \\ \text { researchers' feud } \\ p 400\end{array}\end{aligned}$

\title{
German lab unveils plan to build physicists' next particle collider
}

Alison Abbott and Josette Chen

The next era of high-energy physics will come into sharp focus this weekend when an international team of physicists unveils a proposal for a major linear collider.

The team, based at the DESY particle physics laboratory near Hamburg, will propose the construction of a machine called TESLA - the Tera electron volt Energy Superconducting Linear Accelerator - at an estimated cost of about US\$3 billion. The machine would be a linear electron-positron collider based on superconducting resonators (also known as 'cavities'). It would allow particles to collide at energies of between 500 and 800 gigaelectron volts $(\mathrm{GeV})$.

The announcement will attract keen global interest because both the United States and Japan believe they should host the next major collider project. Physicists from both countries have been jointly developing a proposal for a linear collider that would meet similar energy goals to those of TESLA using conventional, rather than superconducting, resonators to accelerate the electrons. The project is known in the United States as the Next Linear Collider (NLC) and

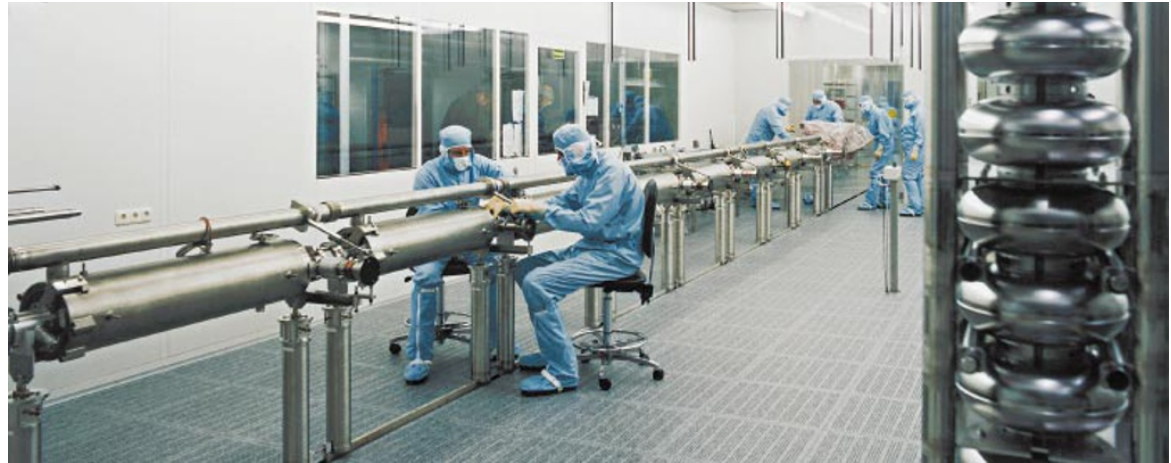

Linear thoughts: DESY staff assemble prototype accelerator parts for the proposed TESLA collider.

in Japan as the Japan Linear Collider (JLC).

The various teams, all of them international, are downplaying the competitive aspect, but each community of physicists would obviously like the next-generation machine to be built on its own territory. Both the United States and Japan are making substantial contributions to another major project, the Large Hadron Collider (LHC) that is being built at CERN, the European Laboratory for Particle Physics, near Geneva. Construction of TESLA in Germany, with the LHC also in Europe, could mark the virtual

\section{No Wellcome money for Celera}

David Adam, London

The Wellcome Trust, the world's largest medical charity, has banned its grant recipients from using its funding to subscribe to the human genome sequence prepared by Celera Genomics. Instead it wants them to use the public human genome sequence, which it partially funded and helped to prepare.

A Wellcome policy statement says that 'no trust funds, including contingency monies, may be used for the purpose of accessing Celera subscription services'. Trust-funded researchers accessing Celera's sequence must do so with money 'from sources wholly independent of the trust."

A spokesperson for Celera said that
Wellcome Trust researchers would still be able to access the company's data: "We have a free site and so presumably they will have access that way."

"There is no evidence that Celera's database offers any scientific advantage," says Mike Dexter, director of the trust. "This is not a ban: we are just trying to get the best value for trust money."

The trust uses revenues from its $\mathfrak{E} 15$ billion (US\$21 billion) asset base to fund biomedical research in UK universities and, to a lesser extent, in the developing world. It distributes about $\mathfrak{E 6 0 0}$ million in grants every year, including funding for the Sanger Centre in Cambridge, the UK arm of the Human Genome Project.

ش ๑ 2001 Macmillan Magazines Ltd eclipse of particle physics in the United States and Japan for a generation.

A linear collider would help physicists to discover what lies beyond the standard model, the theory that describes all elementary particles and the corresponding forces between them. Many aspects of the theory have been fully validated. But one exception is the Higgs boson, the heavy particle that physicists hope to find using either the renovated Tevatron at Fermilab in Illinois (see Nature409, 754-755; 2001) or the LHC.

Both these accelerator rings, which create collisions of heavy particles such as protons, may detect evidence for supersymmetry, a theory that would augment the standard model by finding corresponding 'sparticles' for each known particle. But proton colliders produce messier and more complex collisions than electron-positron colliders, which have long been used to complement them in particle physics investigations.

"The LHC will provide one view beyond the standard model and the electronpositron collider will provide another," says Burt Richter, former director of the Stanford Linear Accelerator Center (SLAC) in California, which has led the US arm of the NLC design.

Both TESLA and the NLC would achieve high enough energies - in the $500 \mathrm{GeV}$ to 1 $\mathrm{TeV}\left(\times 10^{12} \mathrm{eV}\right)$ range - to complement the LHC. But the NLC design uses conventional technologies developed at SLAC and at the Japanese laboratory KEK, which are based on copper resonators. NLC advocates say 
that this will allow the machine to operate at higher frequencies, yielding faster acceleration and a smaller, and therefore potentially cheaper, facility than TESLA.

Another advantage of the NLC design is the technology's established track record. "We already have one at $50 \mathrm{GeV}$, so going to $500 \mathrm{GeV}$ is only a factor of 10 , and we have lots of experience," says Richter.

But the NLC concept received a blow in the past year, when researchers found physical deterioration in the copper cells after 1,000 hours of operation. "We should know by the summer if new designs will overcome these problems," says Steve Holmes, associate director at Fermilab.

More ominously, an initial 1999 cost estimate for the NLC came in at a politically unrealistic $\$ 7.9$ billion. "We need this to be reduced by $25 \%$, preferably by $50 \%$," says Peter Rosen, head of high-energy physics at the US Department of Energy. He says a potential reduction of $30 \%$ has already been achieved.

TESLA's use of superconducting resonators should mean a higher beam intensity and lower operating costs, its advocates say. Compared with the NLC, the radiofrequency devices that excite superconducting resonators are simpler to build. But the largest functioning accelerator using superconducting technology, the Thomas Jefferson National Accelerator Facility in Virginia, operates at only $1 \mathrm{GeV}$.

Albrecht Wagner, DESY's director, believes that the price estimate his team will publish on 23 March will be considered reasonable. But unlike the US estimate, it will exclude labour and operational costs, which could double the actual price.

The TESLA proposal will be assessed by the Wissenschaftsrat, Germany's science council, which will decide whether to recommend it to the government. German research minister Edelgard Buhlman has made positive noises about TESLA, but has said the project will go ahead only with the support of the international particle physics community - and financial support from abroad. But Wagner contends that construction could start within two years.

Political factors are likely to settle the choice of both the site and the design. The US community plans a major gathering of particle physicists in Snowmass, Colorado, this July to look at future priorities. A subpanel of the High Energy Physics Advisory Panel is meanwhile mapping out a 20 -year plan for the discipline.

With substantial funding allocated for building the LHC, Europe is not flush with money for a new collider either, and DESY is trying to promote TESLA as a multidisciplinary facility whose associated freeelectron laser will also be used by materials scientists, chemists and biologists.

\section{More culls planned as Britain wrestles with foot-and-mouth}

\section{David Adam, London}

Up to a million healthy farm animals are to be slaughtered in a fresh attempt to break the stranglehold of foot-and-mouth disease on the British countryside, the government announced last week.

All sheep and pigs within three-kilometre exclusion zones around areas of high infection will be culled. Government vets hope that the mass slaughter will create 'fire-walls' that the infection cannot cross.

Meanwhile, with more than 325 cases of the disease now reported, officials have admitted that attempts to contain the virus among animal herds that were infected before movement restrictions were introduced have failed.

"Some of the new cases we're seeing are down to contiguous infection, things like airborne spread, vehicle movement and people movement," says a spokesman for the Ministry of Agriculture, Fisheries and Food (MAFF).

But he denies that the outbreak is out of control, pointing out that new cases can still be traced back to animals infected during the original outbreak. "We're still saying that [the epidemic] is under control to a certain extent," he says.

But some experts disagree. "The crucial measure is if the transmission potential is self-sustaining," says Roy Anderson, a leading epidemiologist at Imperial College, London. Because each primary infection on a farm is leading to more than one secondary infection, he says, the situation "is quite clearly not under control".

Anderson agrees that the mass slaughter around infection hot-spots is "absolutely the right thing to do". But he is worried about whether other, more isolated cases can be effectively contained.

The epidemic, which broke out last month (see Nature 410, 4; 2001), is the first major outbreak in Britain since 1967. One reason why it has proven to be more difficult to control than the government had hoped is that some infected animals were sold in private deals at cattle markets, so the sales were never officially recorded and the animals could not be traced until their symptoms were observed.

Although the initial stages of any epidemic are the hardest to predict, epidemiologists remain optimistic about the possible control of the disease in mainland Europe. The first case of foot-and-mouth was confirmed in France last week. But France traced and slaughtered all animals that had been imported from Britain in the weeks preceding the initial outbreak, and placed herds

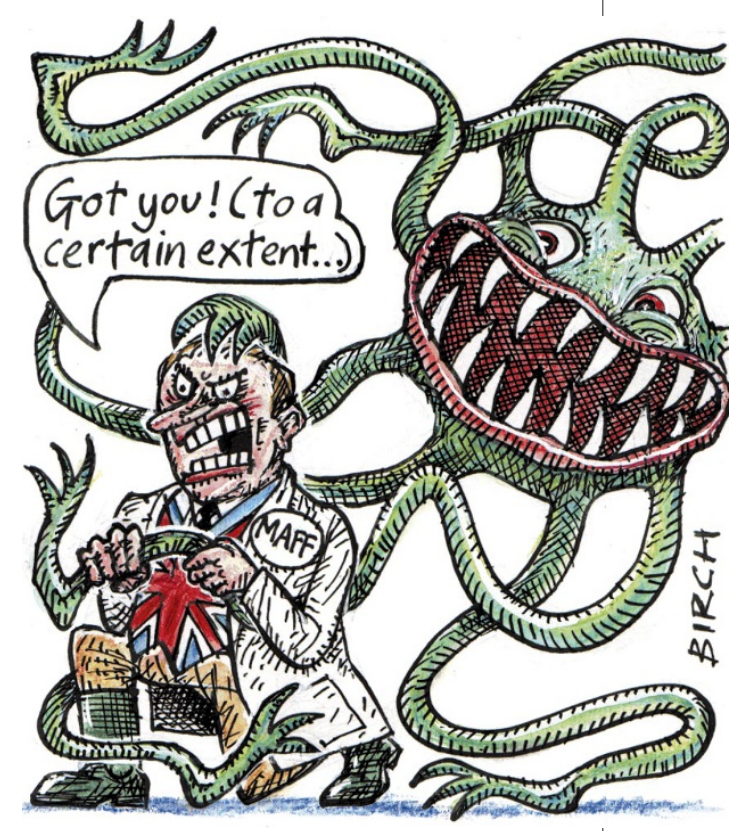

that may have been in contact with them under quarantine and close surveillance. The infected animal was found in one of these herds.

"The French have reacted very quickly and very well," Anderson says. "An epidemic is a non-linear process, therefore action taken in the early stages prevents far more cases than action taken later."

Mark Savay at the National Veterinary Centre in Paris adds that restrictions on animal meetings and transportation were introduced in France within days of the first UK case. "We received clear instructions from the European Commission to do that," he says, adding that other European Union countries would have received orders to do the same.

Controls on meat, livestock and milk imports from Britain, as well as animal movement restrictions, have been tightened in most other European countries. Countries outside Europe, including Japan and the United States, are also acting to keep the virus out, banning imports from Europe and introducing strict checks on travellers.

Vets and epidemiologists agree that modern patterns of animal movement and trade have increased the spread of the infection. It has already spread further in Britain than the 1967-1968 outbreak did in six months. "The number of animals moved and the number of journeys is not that different today but the distances involved are greater," says Chris Bostock, director of the government-funded Institute for Animal Health.

1 http://www.maff.gov.uk/animalh/diseases/fmd/ default.htm 